CLINICAL STUDY

\title{
IGF-I increases the recruitment of GLUT4 and GLUT3 glucose transporters on cell surface in hyperthyroidism
}

\author{
George Dimitriadis ${ }^{1}$, Eirini Maratou ${ }^{2}$, Eleni Boutati ${ }^{1}$, Anastasios Kollias ${ }^{1}$, Katerina Tsegka ${ }^{1}$, Maria Alevizaki ${ }^{3}$, \\ Melpomeni Peppa ${ }^{1}$, Sotirios A Raptis ${ }^{1,2}$ and Dimitrios J Hadjidakis ${ }^{1}$ \\ ${ }^{1}$ Second Department of Internal Medicine, Research Institute and Diabetes Center, University General Hospital 'Attikon', Athens University, 1 Rimini Street, \\ 12462 Haidari, Greece, ${ }^{2}$ Hellenic National Center for Research, Prevention and Treatment of Diabetes Mellitus and its Complications, 10675 Athens, \\ Greece and ${ }^{3}$ Department of Clinical Therapeutics, 11528 Athens University, Athens, Greece \\ (Correspondence should be addressed to G Dimitriadis; Email: gdimi@ath.forthnet.gr,gdimitr@med.uoa.gr)
}

\begin{abstract}
Objective: In hyperthyroidism, tissue glucose disposal is increased to adapt to high energy demand. Our aim was to examine the regulation of glucose transporter (GLUT) isoforms by IGF-I in monocytes from patients with hyperthyroidism.

Design and methods: Blood $(20 \mathrm{ml})$ was drawn from 21 healthy and 10 hyperthyroid subjects. The abundance of GLUT isoforms on the monocyte plasma membrane was determined in the absence and presence of IGF-I $(0.07,0.14$, and $0.7 \mathrm{nM})$ using flow cytometry. Anti-CD14-phycoerythrin monocional antibody was used for monocyte gating. GLUT isoforms were determined after staining the cells with specific antisera to GLUT3 and GLUT4.

Results: In monocytes from the euthyroid subjects, IGF-I increased the abundance of GLUT3 and GLUT4 on the monocyte surface by 25 and $21 \%$ respectively $(P<0.0005$ with repeated measures ANOVA). Hyperthyroidism increased the basal monocyte surface GLUT3 and GLUT4; in these cells, IGF-I had a marginal but highly significant effect $(P=0.003$, with repeated measures ANOVA) on GLUT3 (11\%) and GLUT4 (10\%) translocation on the plasma membrane.

Conclusions: In hyperthyroidism: 1) basal abundance of GLUT3 and GLUT4 on the plasma membrane is increased and 2) the sensitivity of the recruitment of GLUT3 and GLUT4 transporters on the plasma membrane in response to IGF-I is increased. These findings may contribute to the understanding of the mechanism by which hyperthyroidism increases glucose disposal in peripheral tissues.
\end{abstract}

European Journal of Endocrinology 158 361-366

\section{Introduction}

In hyperthyroidism, tissue metabolic rate increases significantly (1). To adapt to high energy demand, cellular rates of basal and insulin-stimulated glucose disposal are generally elevated to increase the rates of glucose oxidation and lactate formation; lactate is then used by the liver to increase the rates of gluconeogenesis and endogenous glucose production $(1,2)$.

Insulin-like growth factor-I (IGF-I) has a structural similarity to insulin (3) and its metabolic effects are considered to be similar to those of insulin $(4,5)$. However, in contrast to insulin, IGF-I is ineffective in suppressing hepatic glucose production (6-8) and has a preferential effect to increase the rates of glycolysis in tissues such as muscle (5). The effects of IGF-I on glucose disposal in hyperthyroidism have never been investigated.

In insulin- or IGF-I-sensitive tissues, three glucose transporter (GLUT) isoforms are expressed: GLUT1, GLUT3, and GLUT4. GLUT1 is responsible for basal glucose transport, while GLUT3 and GLUT4 are responsible for insulin- or IGF-I-stimulated glucose transport (9).
The present study was designed to examine the effects of physiological and maximal levels of IGF-I on the regulation of GLUT3 and GLUT4 isoforms in monocytes from patients with hyperthyroidism. Monocytes are a suitable cell system for this investigation since they have IGF-I receptors that quickly respond to changes in IGF-I concentrations (10-12), and they express all GLUT isoforms involved in glucose transport in insulin- or IGF-I-sensitive tissues (12-14).

\section{Material and methods}

Twenty-one euthyroid subjects (age $37 \pm 2$ years, body mass index $24 \pm 0.7 \mathrm{~kg} / \mathrm{m}^{2}$, thyroxine $\left(\mathrm{T}_{4}\right) 8.3 \pm$ $0.3 \mu \mathrm{g} / \mathrm{dl}$, tri-iodothyronine $\left(\mathrm{T}_{3}\right) 1.3 \pm 0.06 \mathrm{ng} / \mathrm{ml}$, thyrotrophin (TSH) $1.86 \pm 0.4 \mu \mathrm{IU} / \mathrm{ml}$ ) and ten newly diagnosed hyperthyroid subjects with Graves' disease who received no treatment (age $41 \pm 2$ years, BMI $29 \pm$ $0.5 \mathrm{~kg} / \mathrm{m}^{2}, \mathrm{~T}_{4} 13.1 \pm 0.9 \mu \mathrm{g} / \mathrm{dl}, \mathrm{T}_{3} 2.88 \pm 0.3 \mathrm{ng} / \mathrm{ml}$, $\mathrm{TSH}<0.005 \mu \mathrm{IU} / \mathrm{ml}$ ) were used in this study. The subjects were randomly recruited from the outpatient endocrine 
clinic. None of the subjects had a family history of type 2 diabetes.

All subjects were admitted to the hospital at $0700 \mathrm{~h}$ after an overnight fast and had an antecubital vein catheterized. An oral glucose tolerance test was given (75 g glucose dissolved in water) and blood was drawn from the vein before the administration of glucose (at -30 and $0 \mathrm{~min}$ ) and at 15-60-min intervals for $300 \mathrm{~min}$ thereafter and used for measurements of glucose (Yellow Springs Instrument, Yellow Springs, $\mathrm{OH}, \mathrm{USA}$ ) and insulin (RIA, Linco Research, St Charles, MO, USA).

At $-30 \mathrm{~min}, 20 \mathrm{ml}$ blood (into EDTA tubes) was drawn and used for the GLUT experiments.

The protocol was approved by the hospital ethics committee and all subjects gave written informed consent.

\section{Cells and incubations}

Blood was diluted 1:1 (v/v) with (PBS, w/o $\mathrm{Ca}^{2+}$, $\left.\mathrm{Mg}^{2+}\right)$, placed on Histopaque-1077 (1:2, v/v) and centrifuged at $400 \mathrm{~g}$ for $30 \mathrm{~min}$ at $22{ }^{\circ} \mathrm{C}$, to isolate the 'buffy' coat (mononuclear inter-phase layer). Mononuclear cells were then resuspended in PBS and washed twice $\left(150 \mathrm{~g}, 10 \mathrm{~min}\right.$ at $\left.22^{\circ} \mathrm{C}\right)$. Erythrocytes were lysed with BD Pharm Lyse (lysing reagent, BD Biosciences Pharmigen, San Jose, CA, USA). The exact number of cells was determined cytometrically with Flow-Count Fluorospheres (Beckman-Coulter, Miami, FL, USA).

\section{Effect of IGF-I on GLUT expression}

The mononuclear cells were aliquoted at the desired concentration $\left(1 \times 10^{6}\right.$ cells $\left./ \mathrm{ml}\right)$ and incubated for $60 \mathrm{~min}$, at $22^{\circ} \mathrm{C}$, in a buffer $(\mathrm{NaCl} 140 \mathrm{mM}$, HEPES $20 \mathrm{mM}$, KCl $5 \mathrm{mM}, \mathrm{MgSO}_{4} 2.5 \mathrm{mM}$, glucose $5.5 \mathrm{mM}$, $\mathrm{pH}$ 7.4), containing different concentrations of IGF-I (Millipore Corporation, Billerica, MA, USA) or insulin (Sigma Diagnostics). Termination of incubation was achieved with the addition of cytochalasin-B $(10 \mu \mathrm{M}$; Sigma Diagnostics).

\section{Immunofluorescence analysis of GLUT isoforms}

Surface GLUT isoforms were determined after staining the cells with anti-GLUT antisera. The antibodies used were mouse anti-GLUT3 (R\&D Systems, Minneapolis, MN, USA) and rabbit anti-GLUT4 $(0.1 \mathrm{mg} / \mathrm{ml}$, polyclonal antibody, Chemicon International); each corresponded to the exofacial loop of the human GLUT.

Since the antibodies were not fluorochrome conjugated, they were labeled with the Zenon Alexa Fluor 488 Rabbit immunogloubulin class G (IgG) labeling kit or Zenon Alexa Fluor 488 Mouse $\operatorname{IgG}_{2 \mathrm{~b}}$ (Invitrogen, Carlsbad, CA, USA). Cells were incubated for $30 \mathrm{~min}$ with Alexa Fluor 488-conjugated immunoglobulin in a ratio $1 \times 10^{6}$ cells $/ 1 \mu \mathrm{g}$ of immunoglobulin under mild constant shaking. The monocyte fraction was simultaneously stained with anti-CD14-phycoerythrin (PE) monclonal antibody (MAB) (BD Biosciences). After the incubation with the antisera and a wash with PBS, cells were fixed with $0.1 \%(\mathrm{w} / \mathrm{v})$ paraformaldehyde.

No permeabilization step was required due to the fact that the study was focused on the transporters located on the surface of the cell membrane. A histogram of log green fluorescence of each GLUT isoform was used for the determination of the mean fluorescence intensity (MFI) of each sample.

\section{Validation of specificity of GLUT antisera}

The specificity of the different GLUT antisera was evaluated by staining cells with isotype controls suitable for each antisera and the blockage of Fc receptors prior to staining, as previously described $(13,14)$.

\section{Elimination of crosstalk between insulin receptor and IGF-I receptor}

To exclude the possibility of non-specific action of IGF-I through the insulin receptor, preliminary experiments were done, in which cells were incubated for $30 \mathrm{~min}$ with anti-insulin receptor antibody $(5 \mu \mathrm{g} / \mathrm{ml}$, Chemicon International) prior to the addition of IGF-I. The effect of IGF-I on GLUT translocation was not eliminated indicating a specific binding of IGF-I to its receptor (data not shown).

\section{Flow cytometric analysis}

Two-color flow cytometric analysis was performed on a BD FACSCalibur four-color flow cytometer (BD Biosciences) equipped with two air-cooled lasers: a $15 \mathrm{~mW}$ Argon laser (488 nm) and a Red Diode laser (632 nm). The emission of two fluorochromes was recorded through specific band pass filters: $525 \mathrm{~nm}$ for fluorescein isothiocyanate and $575 \mathrm{~nm}$ for PE. The flow cytometer was regularly checked by using standard BD Calibrite 3 beads (BD Biosciences) for photomultiplier tube (PMT) voltage adjustment, color compensation setup, and sensitivity test. Compensation settings were further optimized after running samples individually stained with a single monoclonal with each different fluorochrome and run through the flow cytometer. Cells were gated on a forward scatter (FS) versus $90^{\circ}$ light scatter-side scatter (SS) plot based on their morphological features and on FL2 versus side scatter (SS) dot plot where a PE-conjugated MAB was used to trace the cells of interest. Green fluorescence (anti-GLUT3 and anti-GLUT4 Alexa Fluor 488) was displayed on FL1 single histogram gated on the previous two plots. An appropriate discriminator was set on the FS parameter 
to exclude small debris and other cell fragments. Data acquisition and analysis were performed using the BD CELL Quest Pro software (BD Biosciences).

\section{Statistical analysis}

Data in text and figures are presented as MFI; this parameter is the fluorescence intensity detected in a gated population of cells (no < 5000) divided by the number of events (cells) in the gated area. IGF-I and insulin dose-response curves were analyzed with repeated-measures ANOVA.

To examine the differences between hyperthyroid and euthyroid subjects independently of BMI and age, we performed an analysis of covariance with glucose, insulin, or GLUT levels as dependent variables; thyroid status as fixed factor; and BMI and age as covariates.

\section{Results}

Postprandial plasma glucose and insulin levels were increased in the hyperthyroid versus euthyroid subjects (Fig. 1). None of the subjects had a diabetic oral glucose tolerance test according to the American Diabetes Association criteria (fasting plasma glucose values higher than $126 \mathrm{mg} / \mathrm{dl}$ and plasma glucose values at $120 \mathrm{~min}$ higher than $200 \mathrm{mg} / \mathrm{dl}$ ); two of the subjects had impaired glucose tolerance justified by their hyperthyroid state (plasma glucose values at $120 \mathrm{~min}$, $176 \mathrm{mg} / \mathrm{dl}$, and $190 \mathrm{mg} / \mathrm{dl}$ respectively).
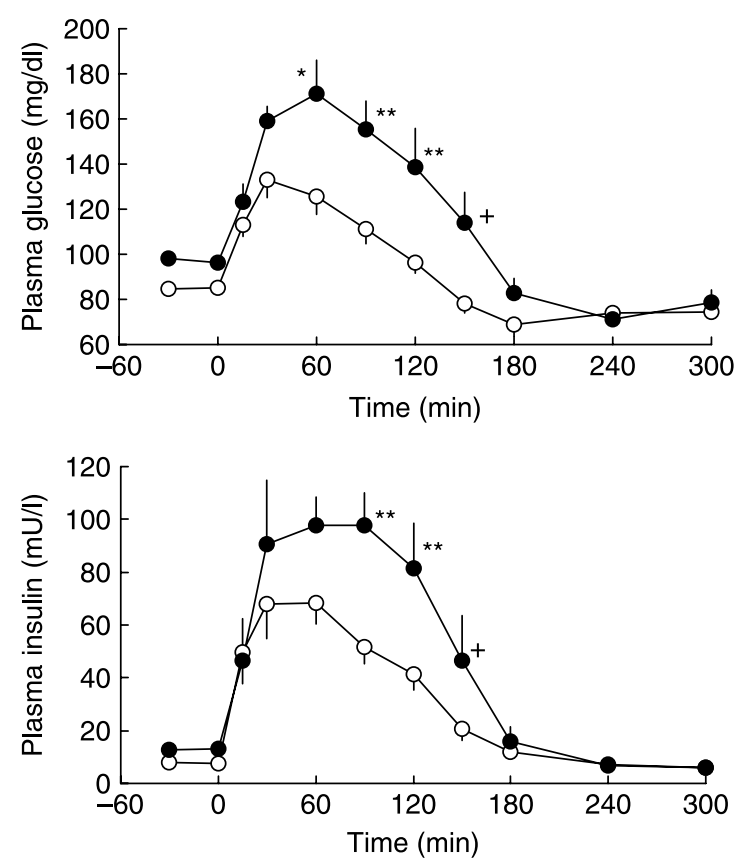

Figure 1 Plasma glucose and insulin levels (mean \pm s.E.M.) in euthyroid (open circles) and hyperthyroid subjects (closed circles) after an oral glucose tolerance test (75 g glucose); ${ }^{+} P<0.05$, ${ }^{\star} P=0.01,{ }^{\star *} P<0.01$.
In monocytes from euthyroid subjects, insulin increased GLUT4 and GLUT3 isoforms on the plasma membrane by 39 and $34 \%$ respectively $(P<0.005$ with ANOVA; Fig. 2). In these cells, IGF-I increased GLUT4 and GLUT3 isoforms on the plasma membrane by 21 and $25 \%$ respectively ( $P<0.005$ with ANOVA; Fig. 3$)$.

In monocytes from hyperthyroid subjects, increasing concentrations of insulin had a statistically significant effect on the translocation of GLUT4 $(10 \%, P=0.013$ with ANOVA) and GLUT3 $(21 \%, P<0.0001$ with ANOVA) isoforms on the plasma membrane (Fig. 2). In these cells, IGF-I had a marginal but statistically significant effect on the translocation of GLUT4 (10\%, $P=0.003$ with ANOVA) and GLUT3 $(11 \%, P=0.003$ with ANOVA) isoforms on the plasma membrane (Fig. 3 ).

A comparison between euthyroid and hyperthyroid groups showed that hyperthyroidism increased the abundance of GLUT4 and GLUT3 isoforms on the monocyte surface in the absence of insulin or IGF-I. When insulin levels were increased to $0.7 \mathrm{nM}$, the abundance of GLUT3 on the monocyte surface in the hyperthyroid subjects was increased, while that of GLUT4 was not significantly different from values in the euthyroid subjects (Fig. 2). When IGF-I levels were increased to $0.7 \mathrm{nM}$, the abundance of GLUT4 transporters on the monocytes surface in hyperthyroid subjects was increased, while that of GLUT3 was not
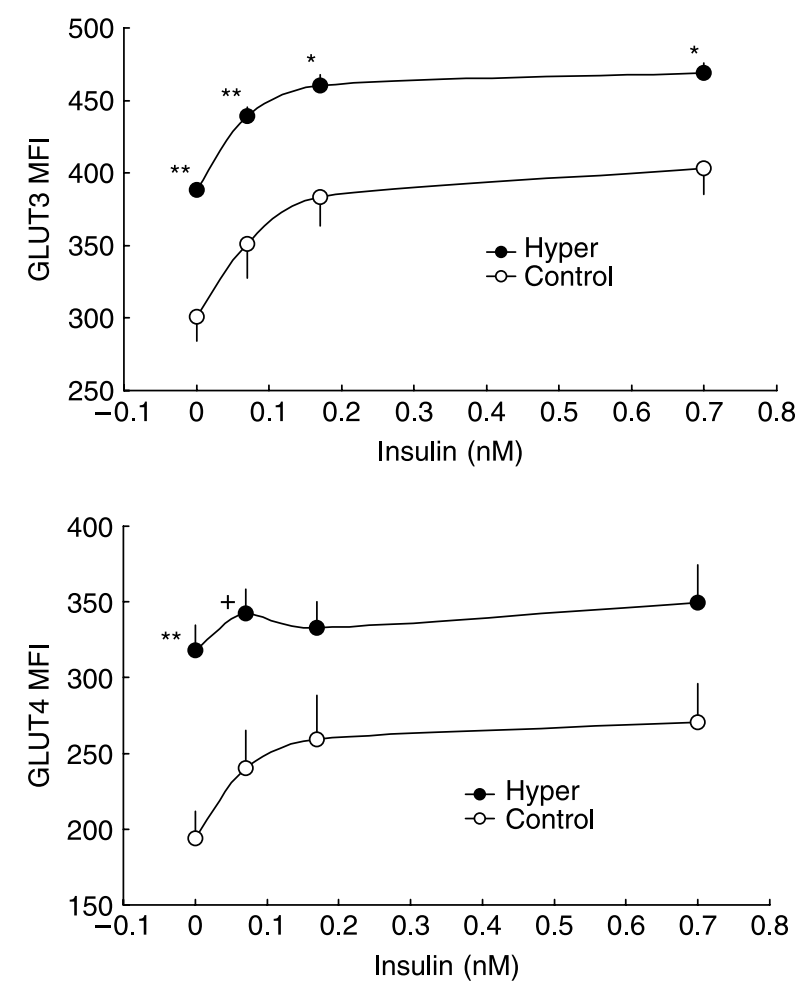

Figure 2 Effects of insulin on GLUT3 and GLUT4 increase (mean \pm S.E.M.) on the plasma membrane of monocytes isolated from euthyroid (open circles) and hyperthyroid subjects (closed circles). $\mathrm{MFI}$, mean fluorescence intensity; ${ }^{+} P<0.05,{ }^{\star} P=0.01,{ }^{\star *} P<0.01$. 

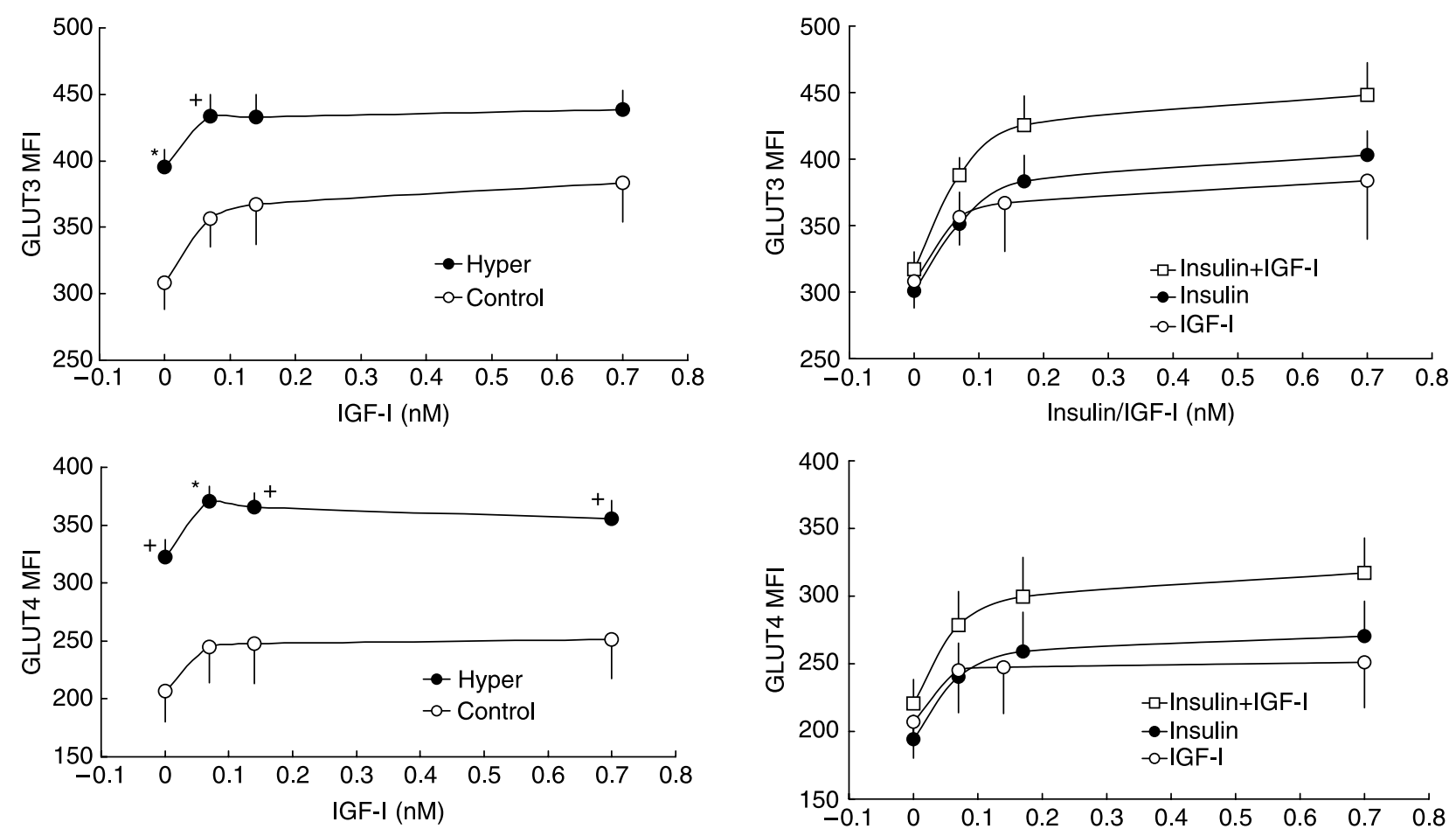

Figure 3 Effects of IGF-I on GLUT3 and GLUT4 increase (mean \pm S.E.M.) on the plasma membrane of monocytes isolated from euthyroid (open circles) and hyperthyroid subjects (closed circles). MFI, mean fluorescence intensity; ${ }^{+} P<0.05,{ }^{\star} P=0.01,{ }^{\star \star} P<0.01$.

significantly different from values in the euthyroid subjects (Fig. 3).

Experiments were also performed with insulin and IGF-I present either alone or in combination. When the two peptides were added simultaneously, there was a slight increase in the translocation of GLUT3 and GLUT4 transporters on the plasma membrane versus the experiments in which the two peptides were added alone, but the differences were not statistically significant (Fig. 4).

\section{Discussion}

In agreement with previous results, glucose tolerance was impaired in the hyperthyroid subjects $(2,16)$; this is due to the insulin resistance primarily at the liver since glucose uptake in peripheral tissues is generally found to be either normal or increased $(2,16,17)$.

Glucose transport controls the rate of glucose utilization and is therefore an important regulatory step in cell metabolism (18). In hyperthyroidism, absolute rates of glucose transport in peripheral tissues (such as muscle or adipose tissue) are found to be increased, in order to adapt to high energy demand $(2,16,17)$. Our results suggest that hyperthyroidism increases the sensitivity of the recruitment of GLUT3 and GLUT4 transporters to the cell surface in response

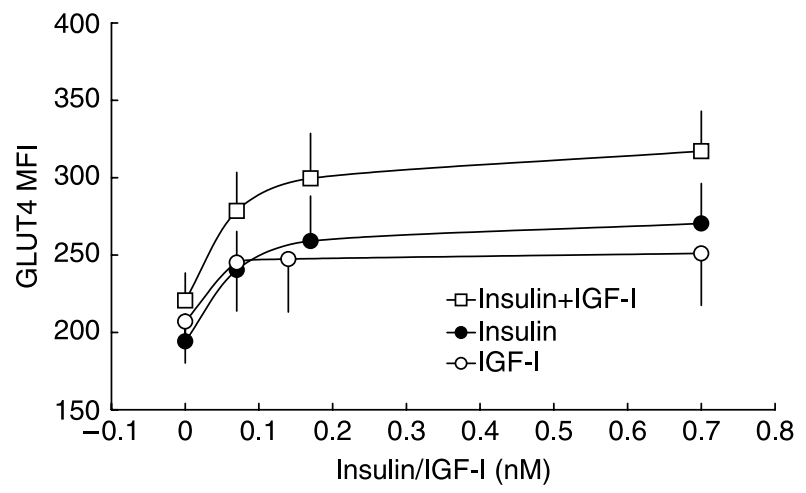

Figure 4 Effects of insulin alone (closed circles), IGF-I alone (open circles), and insulin plus IGF-I (at a fixed concentration of $0.14 \mathrm{nM}$, open squares) on GLUT3 and GLUT4 increase (mean \pm S.E.M.) on the plasma membrane of monocytes isolated from euthyroid subjects. MFI, mean fluorescence intensity.

to IGF-I, thus contributing to increased glucose transport rates.

\section{Validation of techniques}

The observations in our study were made using monocytes. These cells express all three isoforms responsible for glucose transport (GLUT1, GLUT3, and GLUT4) and have IGF-I receptors that respond quickly to the changes in IGF-I concentrations (10-12). Monocytes have been previously used as a model cell system in patients with diabetes mellitus, obesity, or hyperthyroidism to investigate defects in insulin- or IGF-I-stimulated glucose transport $(12,15,19,20)$.

The effects of IGF-I on GLUT isoform abundance were examined by flow cytometry. This technique has previously been used to investigate GLUT expression on the surface of the cell membrane under various conditions $(15,21,22)$. Our study extends these observations and illustrates that flow cytometry can also be used to measure the abundance of GLUT transporters on the surface membrane, during stimulation by IGF-I.

The specificity of the antisera used to determine GLUT transporters on the monocyte surface with flow cytometry has been previously validated by western 
blotting (15), staining of monocytes with mouse $\operatorname{IgG}_{1}$ negative control (13), and treatment with wortmannin, a phosphatidylinositol 3-kinase inhibitor (15). The results suggest that flow cytometry is a valid, simple, quick, and reproducible method to evaluate the effects of IGF-I on the GLUT translocation process.

\section{Effects of IGF-I on GLUT isoforms}

The results presented in our study are of physiological significance since the concentrations of IGF-I used were within the normal physiological range.

In the hyperthyroid subjects, basal levels of GLUT4 and GLUT3 were increased on the monocyte surface, but the responsiveness of the recruitment of these transporters to IGF-I was less than that of the euthyroid subjects (Fig. 3). These results suggest that, under these metabolic conditions, most of the GLUT4 and GLUT3 transporters may migrate from their storage pools to the cell surface: this could lead to a near-maximal response at low levels of IGF-I (i.e. an increase in sensitivity), but a decreased response when IGF-I is elevated.

The involvement of GLUT4 and GLUT3 in the glucose uptake process in the hyperthyroid state has previously been reported $(15,23)$. In skeletal muscle or isolated monocytes, the total number of GLUT4 and the fractional partitioning to the plasma membrane has been found to be increased $(23,24)$. As regards to the GLUT3 isoform, its cellular expression increases in hyperthyroidism and this GLUT may become primarily responsible for the stimulation of glucose uptake (15).

The results of the present study (Fig. 2) and the previous investigations $(15,23,24)$ have shown that the sensitivity of GLUT4 and GLUT3 translocations to insulin increases in hyperthyroidism. Our results extend these observations and suggest that in the hyperthyroid state, the increase in cellular glucose transport is caused, in part, by the increased sensitivity of the tissues to IGF-I.

Several studies have shown that monocytes and macrophages utilize glucose at high rates and their metabolism is modified by insulin and thyroid hormones (25-29). In rat macrophages, hyperthyroidism was shown to increase the rates of glucose uptake (28). In these cells, glycolysis was evaluated by measuring the activity of hexokinase and Krebs cycle by measuring the activity of citrate synthase and the decarboxylation of [U- ${ }^{14}$ C]glucose (27-29). In macrophages from normal rats, insulin was shown to increase the activities of hexokinase and citrate synthase as well as the decarboxylation of glucose; in contrast, in macrophages from hyperthyroid rats, the activity of hexokinase was increased, whereas both the activity of citrate synthase and the decarboxylation of [U- $\left.{ }^{14} \mathrm{C}\right]$ glucose were decreased suggesting an increase in the rates of glycolysis and a decrease in the rates of glucose oxidation (27-29). These results are in agreement with the experiments performed in the skeletal muscle of rats, which were made hyperthyroid after treatment with triiodothyronine for 2 ,
5, or 10 days: although the sensitivity of glycogen synthesis to insulin was clearly decreased and that of lactate formation was increased after all three experimental conditions, the sensitivity of glucose oxidation to insulin was increased only after 5 or 10 days treatment, suggesting that in hyperthyroidism, there is a preferential increase in glycolysis and lactate formation relative to glucose oxidation and storage in skeletal muscle (30). Lactate is of major importance as a substrate in the hyperthyroid state to increase the rate of gluconeogenesis in the liver $(1,31,32)$.

In a previous study, lipid metabolism was investigated in mouse monocytes after incubation with $\left[1-{ }^{14} \mathrm{C}\right]$ oleate (33). Of the radioactivity associated with lipid, $80 \%$ of oleate was shown to be incorporated into triglycerides, $18 \%$ was incorporated into phospholipids, and $2 \%$ was recovered as non-esterified fatty acids. It is therefore possible that triglycerides represent a major fuel store for these cells, and whenever fatty acids are available they are taken up and incorporated into lipid to act as an important fuel reserve (33). Under hyperthyroid conditions, this function of monocytes is expected to be of major significance since non-esterified fatty acids represent an important substrate to cover the increased energy demands (16).

To compare the effects of IGF-I and insulin on GLUT3 and GLUT4 translocation in monocytes, experiments were performed with the two peptides present either alone or in combination. When insulin and IGF-I were added simultaneously, there was a slight increase in the translocation of GLUT3 and GLUT4 transporters on the plasma membrane versus the experiments in which the two peptides were added alone, but the differences were not statistically significant (Fig. 4). These results suggest that IGF-I induces a near-maximal translocation of the GLUTs from the intracellular pool to the plasma membrane and therefore does not have an additive effect with insulin (5).

In summary, hyperthyroidism increases the basal abundance of GLUT3 and GLUT4 on the monocyte surface membrane. During the stimulation by IGF-I, hyperthyroidism increases the sensitivity of the recruitment of both GLUT3 and GLUT4 isoforms to the monocyte surface. If the findings in monocytes reflect those in other IGF-I-sensitive tissues, they may explain the increment in glucose disposal observed in peripheral tissues in the hyperthyroid state to cover the increased energy demands.

\section{Acknowledgements}

We thank Ms V Frangaki, RN for help with the experiments. This project has been co-funded by the European Social Fund and National Resources (EPEAEK II) PYTHAGORAS II. 


\section{References}

1 Dimitriadis G \& Raptis S. Thyroid hormone excess and glucose intolerance. Experimental and Clinical Endocrinology and Diabetes $2001109225-239$.

2 Dimitriadis G, Baker B, Marsh M, Mandarino L, Rizza R, Bergman R, Haymond M \& Gerich J. Effect of thyroid hormone excess on action, secretion and metabolism of insulin in humans. American Journal of Physiology 1985248 E593-E601.

3 Rinderknecht E \& Humbel R. The amino acid sequence of human insulin-like growth factor I and its structural homology with proinsulin. Journal of Biological Chemistry $19782532769-2776$.

4 Zapf J, Hauri C, Waldvogel M \& Froesch R. Acute metabolic effects and half-lives of intravenously administered insulin-like growth factors 1 and 2 in normal and hypophysectomized rats. Journal of Clinical Investigation 198677 1768-1775.

5 Dimitriadis G, Parry-Billings M, Bevan S, Dunfer D, Piva T, Krause U, Wegener G \& Newsholme EA. Effects of insulin-like growth factor 1 on the rates of glucose transport and utilization in rat skeletal muscle in vitro. Biochemical Journal $1992 \mathbf{2 8 5}$ 269-274.

6 Jacob R, Barrett E, Plewe G, Fagin R \& Sherwin R. Acute effects of insulin-like growth factor I on glucose and amino acid metabolism in the awake fasted rat. Comparison with insulin. Journal of Clinical Investigation 198983 1717-1723.

7 Giacca A, Gupta R, Efendic S, Hall K, Skottner A, Lickley L \& Vranic M. Differential effects of IGF-I and insulin on glucoregulation and fat metabolism in depancreatized dogs. Diabetes 199039 340-347.

8 Jakob R, Sherwin R, Bowen L, Fryburg D, Fagin K, Tamborlane W \& Shulman G. Metabolic effects of IGF-I and insulin in spontaneously diabetic BB/w rats. American Journal of Physiology $1991260262-268$.

9 Gould G \& Holman G. The glucose transporter family: structure, function and tissue-specific expression. Biochemical Journal 1993 295 329-341.

10 Stuart C, Meehan R, Neale L, Cintron NM \& Furlanetto RW. Insulin-like growth factor 1 binds selectively to human peripheral blood monocytes and B-lymphocytes. Journal of Clinical Endocrinology and Metabolism 199172 1117-1124.

$11 \mathrm{Xu} \mathrm{X,} \mathrm{Mardell} \mathrm{C,} \mathrm{Xian} \mathrm{CJ,} \mathrm{Zola} \mathrm{H} \mathrm{\&} \mathrm{Read} \mathrm{LC.} \mathrm{Expression} \mathrm{of}$ functional insulin-like growth factor 1 receptor on lymphoid cell subsets of rats. Immunology 199585 394-399.

12 Estrada E, Elliott E, Zinman B, Poon I, Liu Z, Klip A \& Daneman D. Regulation of glucose transport and expression of GLUT3 transporters in human circulating mononuclear cells: studies in cells from insulin-dependent and nondiabetic individuals. Metabolism 199443 591-598.

13 Dimitriadis G, Maratou E, Boutati E, Psarra K, Papasteriades CH \& Raptis SA. Evaluation of glucose transport and its regulation by insulin in human monocytes using flow cytometry. Cytometry Part A 2005 64A 27-33.

14 Maratou E, Dimitriadis G, Kollias A, Boutati E, Lambadiari V, Mitrou P \& Raptis SA. Glucose transporter expression on the plasma membrane of resting and activated white blood cells. European Journal of Clinical Investigation 200737 282-290.

15 Dimitriadis G, Maratou E, Alevizaki M, Boutati E, Psarra K, Papasteriades C \& Raptis SA. Thyroid hormone excess increases basal and insulin-stimulated recruitment of GLUT3 glucose transporters on cell surface. Hormone and Metabolic Research 200537 15-20.

16 Dimitriadis G, Mitrou P, Lambadiari V, Boutati E, Maratou E, Koukkou E, Tzanella M, Thalassinos N \& Raptis SA. Glucose and lipid fluxes in the adipose tissue after meal ingestion in hyperthyroidism. Journal of Clinical Endocrinology and Metabolism $2006911112-1118$.
17 Dimitriadis G, Parry-Billings M, Bevan S, Leighton B, Krause U, Piva T, Challiss J, Wegener G \& Newsholme EA. The effects of insulin on transport and metabolism of glucose in skeletal muscle from hyperthyroid and hypothyroid rats. European Journal of Clinical Investigation 199727 475-483.

18 Kahn B. Glucose transport: a pivotal step in insulin action. Diabetes $1996451644-1654$

19 Rizza R, Mandarino L \& Gerich J. Mechanism and significance of insulin resistance in non-insulin dependent diabetes mellitus. Diabetes $198130990-995$.

20 Olefsky J, Kolterman O \& Scarlett J. Insulin action and insulin resistance in obesity and non-insulin dependent diabetes mellitus. American Journal of Physiology 1982243 E15-E30.

21 Aller C, Ehlman S, Gilman-Sachs A \& Snyder A. Flow cytometric analysis of glucose transport in rat brain cells. Cytometry 199727 262-268.

22 Rauchman M, Wasserman J, Cohen D, Perkins D, Hebert S, Milford E \& Gullans S. Expression of GLUT2 c-DNA in human B lymphocytes: analysis of glucose transport using flow cytometry. Biochimica et Biophysica Acta $19921111231-238$.

23 Weinstein S, O’Boyle E \& Haber R. Thyroid hormones increase basal and insulin-stimulated glucose transport in skeletal muscle: the role of GLUT4 glucose transporter expression. Diabetes 1994 43 1185-1189.

24 Casla A, Rovira A, Wells J \& Dohm L. Increased glucose transporter (GLUT4) protein expression in hyperthyroidism. Biochemical and Biophysical Research Communications 1990171 $182-188$.

25 Newsholme P, Curi R, Gordon S \& Newsholme EA. Metabolism of glucose, glutamine, long-chain fatty acids and ketone bodies by murine macrophages. Biochemical Journal 1986239 121-125.

26 Bieger W, Weicker H \& Michl J. Transport and utilization of aminoacids and glucose in human monocytes: activation of glucose metabolism by insulin. Journal of Clinical Endocrinology and Metabolism 198050 1121-1126.

27 Costa Rosa LFBP, Cury Y \& Curi R. Effects of insulin, glucocorticoids and thyroid hormones on the activities of key enzymes of glycolysis, glutaminolysis, the pentose-phosphate pathway and the Krebs cycle in rat macrophages. Journal of Endocrinology 1992135 213-219.

28 Costa Rosa LFBP, Safi DA \& Curi R. Effect of hypo- and hyperthyroidism on the function and metabolism of macrophages in rats. Cell Biochemistry and Function 199513 141-147.

29 Costa Rosa LFBP, Safi DA, Cury Y \& Curi R. The effect of insulin on macrophage metabolism and function. Cell Biochemistry and Function 199614 33-42.

30 Dimitriadis G, Leighton B, Vlachonikolis I, Parry-Billings M, Challiss RAJ, West D \& Newsholme EA. Effects of hyperthyroidism on the sensitivity of glycolysis and glycogen synthesis to insulin in the soleus muscle of the rat. Biochemical Journal 1988253 87-92.

31 Huang M \& Lardy H. Effect of thyroid states on the Cori cycle, glucose-alanine cycle and futile cycling of glucose metabolism in rats. Archives of Biochemistry and Biophysics 1981209 41-51.

32 Sandler M, Robinson R, Rabin D, Lacy W \& Abumrad N. The effect of thyroid hormones on gluconeogenesis and forearm metabolism in man. Journal of Clinical Endocrinology and Metabolism $1983 \mathbf{5 6}$ 479-485.

33 Newsholme P \& Newsholme EA. Rates of utilization of glucose, glutamine and oleate and formation of end-products by mouse peritoneal macrophages in culture. Biochemical Journal 1989261 211-218.

Received 5 December 2007

Accepted 8 December 2007 